\title{
Risk Management on Pre-Exposure Prophylaxis Adherence of Men Who Have Sex with Multiple Men: A Multicenter Prospective Cohort Study
}

\author{
Jiaxiu Liu (iD ${ }^{1,2}$ \\ Ruibin Deng' \\ Bing Lin' \\ Hong Pan' \\ Yuwen Gao' \\ Jianghong $\mathrm{Dai}^{3}$ \\ Hao Liang ${ }^{4}$ \\ Ailong Huang ${ }^{5}$ \\ Xiaoni Zhong (D)
}

'School of Public Health and Management, Chongqing Medical University, Chongqing, 4000I6, People's Republic of China; ${ }^{2}$ School of Medical Information, Chongqing Medical

University, Chongqing, People's Republic of China; ${ }^{3}$ Department of Epidemiology and Health Statistics, School of Public Health, Xinjiang Medical University, Xinjiang, People's Republic of China; ${ }^{4}$ Department of Epidemiology and Medical Statistics, School of Public Health, Guangxi Medical University, Nanning, People's Republic of China; ${ }^{5} \mathrm{Key}$ Laboratory of Molecular Biology on Infectious Diseases, Ministry of

Education, Chongqing Medical University, Chongqing, People's Republic of China

Correspondence: Xiaoni Zhong School of Public Health and Management, Chongqing Medical University, I Yixue Road, Chongqing, 400016, People's

Republic of China

Tel +86 I3308368059

Email zhongxiaoni@cqmu.edu.cn
Background: Men who have sex with multiple men (MSMM) belong to a high-risk group for HIV infection, and pre-exposure prophylaxis (PrEP) is an effective measure to prevent the infection. However, few studies on PrEP adherence by MSMM in China exist. We aimed to explore the protective motivation-related factors for PrEP adherence in an HIV-negative MSMM population in Western China and to provide a reference for future risk management and effective prevention strategies.

Methods: Data were collected from a 2-year follow-up cohort study of PrEP in MSM in China. Rogers' protective motivation theory (PMT) was used to study the PrEP adherence of MSMM, and logistic regression was performed to analyze the influencing factors of PrEP adherence.

Results: A total of 496 MSMM were included in the study: 299 (60.28\%) of them in the good adherence group and $197(39.72 \%)$ in the poor adherence group. The threat assessment scores of the good and poor adherence groups were $2.15 \pm 0.59$ and $2.06 \pm 0.47$, respectively, and the response assessment scores were $2.81 \pm 0.62$ and $2.74 \pm 0.62$, respectively. Poor PrEP adherence was associated with on-demand PrEP medication $(\mathrm{OR}=0.670)$, students at school $(\mathrm{OR}=1.837)$, occasional condom use $(\mathrm{OR}=1.621)$, and good HIV knowledge $(\mathrm{OR}=0.659)$. The higher the threat assessment score, the higher the susceptibility; and the lower the response cost, the stronger the protection motivation and the less likely MSMM were to have poor adherence.

Conclusion: On-demand PrEP medication is more conducive to adherence. Preventive management should focus on MSMMs who are students at school, those who occasionally use condoms, and those with poor HIV knowledge. Improving threat perception and susceptibility, and controlling and reducing the response cost can effectively improve PrEP adherence, and the subsequent application of PMT during intervention research can provide a reference for HIV prevention in MSMM.

Keywords: MSM, multiple sexual partners, PrEP, adherence, protective motivation theory, Western China

\section{Introduction}

Acquired immunodeficiency syndrome (AIDS) is a major global public health problem. By the end of 2017, there were 36.9 million people infected with human immunodeficiency virus (HIV) worldwide, including 1.8 million new infections. ${ }^{1}$ Most HIV infections in China are sexually transmitted, and the proportion of HIV transmissions caused by the homosexual behavior of men who have sex with men (MSM) is on the rise, ${ }^{2,3}$ from $3.4 \%$ in 2007 to about $28.0 \%$ in $2017^{4,5}$. 
Moreover, UNAIDS found that MSM are 19 times more likely to be infected with HIV than other individuals; ${ }^{6}$ and, men who have sex with multiple men (MSMM) present a higher risk of infection than other men. ${ }^{7}$

Studies in America have shown that MSM who have intercourse with multiple sexual partners present a higher risk of HIV transmission, ${ }^{8}$ and two national cross-sectional surveys conducted in Brazil in 2009 and 2016 also confirmed this finding. ${ }^{9}$ Moreover, studies in China have also found that MSM populations having multiple sexual partners and unprotected intercourse present an increased risk for HIV infection; ${ }^{10}$ more than $80 \%$ of MSM had experienced unprotected anal sex in the previous 6 months, nearly $60 \%$ of MSM had 2 or more sexual partners, and the percentage of MSM using condoms was less than $40 \%{ }^{7,11}$ Thus, the focus on this high-risk group of MSMM is important to achieve the global goal of "END AIDS" in 2030.

Pre-exposure prophylaxis (PrEP) is the most promising HIV prevention strategy, and its effectiveness and safety has been confirmed in international clinical trials. ${ }^{12-14}$ Most of those have concluded that the effectiveness of PrEP depends mainly on adherence. ${ }^{12}$ Many studies have found that MSM populations have poor PrEP adherence (especially those in the MSMM category) and the number of sexual partners is correlated with the adherence level. ${ }^{15,16}$ However, China lacks research on the PrEP adherence of its MSMM populations, and most studies have usually focused on the sexual behavior characteristics of MSMM. Therefore, our study focuses on PrEP adherence in an MSMM population to gather data for applicable HIV prevention strategies.

Global prevention and control strategies have gradually made HIV/AIDS a preventable and controllable chronic disease, and strategies to effectively improve the PrEP adherence have become particularly important. The protection motivation theory (PMT) has been widely used in the field of medication adherence research for the study of social psychological factors ${ }^{17,18}$ that affect diseases such as diabetes; PMT can be used to explore the motivation factors of individuals that affect their behaviors. The theory has not been applied to the study of MSMM PrEP adherence in China. This study built a theoretical model of protection motivation from a social psychology perspective to explore the factors related to MSMM PrEP adherence in Western China. Our model should be useful as a scientific reference for risk management of PrEP adherence, and effective prevention and precise intervention strategies for MSMM.

\section{Materials and Methods Participants and Procedure}

From April 2013 to March 2015, participants were recruited in four research sites in Chongqing, Guangxi, Xinjiang, and Sichuan provinces, using a non-probability sampling method (including a non-governmental organization (NGO), peer introductions, and core members "snowball", HIV voluntary counseling and testing (VCT) outpatient service, QQ and WeChat). We set seven inclusion criteria: the provision of a signed informed consent; age between 18 and 65 years; a negative HIV antibody test result; frequency of sexual intercourse once every 2 weeks or more; intercourse with one or more male sexual partners a month before the trial; willingness to take research medication under the guidance and adhere to follow-up arrangements; and, finally, willingness to participate in the trial for 96 weeks. The exclusion criteria included a positive HIV antibody test result at the time of screening; the presence of a disease that seriously affected the development of the trial; having received other study medications 3 months before the screening; having a history of severe allergies; being unable or unwilling to provide an informed consent or unable to comply with the trial requirements; having only one male partner or less during the 6 months before the trial or not reporting the number of sexual partners; failure to complete at least one follow-up survey; abstinence from sexual intercourse during the 96-week follow-up period.

\section{Study Design}

This study was a prospective cohort study, "Study on the prevention of new HIV infection by taking antiviral drugs before and after sexual behavior in MSM population", which was initiated by the Ministry of Science and Technology of China. The prophylaxis protocol made use of tenofovir disoproxil fumarate (TDF; $300 \mathrm{mg} /$ tablets, produced by Pharmacare Limited Trading as Aspen Pharmacare; approval number H20080319). After the baseline survey, the men in the study were randomly assigned to one of three groups: daily PrEP group (one 300-mg pill daily), on-demand PrEP group (a single pill 48-24 hours before and one pill within 2 hours after a sexual exposure), and blank control group (only included 
in the queue management without taking any drugs) which is not the research content of this paper.

All participants were offered standard HIV prevention and intervention services, including HIV testing, counseling, free condom distribution, and STD (sexually transmitted disease) management. For the baseline survey, the participants were asked to fill in a structured questionnaire, and they were issued TDF pills for the first time. After that, follow-up surveys were conducted every 12 weeks (on weeks 12, 24, 36, 48, 60, 72, 84, and 96) and included HIV tests and medication and sexual behavior surveys in the PrEP medication group; in addition, participants were given TDF pills for the next 12 weeks, the longest follow-up time was 2 years.

We defined HIV positivity criteria based on an initial HIV antigen-antibody screening with a fourth-generation enzyme-linked immunosorbent assay (ELISA): If the test results were positive, then the samples were retested with an HIV 1 and 2 antibody diagnostic kit (colloidal selenium method). If retest results were positive, participants were reported as being HIV positive.

\section{Study Contents and Measurements Social Demographic Characteristics}

Social demographic variables included age, urban and rural residential areas, ethnic groups, education level, employment status, marital status (marriage with women), and personal monthly income.

\section{Sexual Behavior Characteristics}

The factors related to sexual behaviors in this study included the following variables: position during anal sexual intercourse with men (only insertive anal sex, "1"; only receptive anal sex, "0"; both but mainly "1", both but mainly " 0 ", both equally), number of temporary male sexual partners during the 6 months before the survey, number of female sexual partners during the 6 months before the survey, frequency of seeking sexual partners on the Internet during the 6 months before the survey (often, sometimes or occasionally, never), whether commercial sexual services had been purchased during the 6 months before the survey, frequency of condom use when having sexual intercourse with men (always, occasionally, never), and whether the individual had been diagnosed with an STD during the 6 months before the survey.

\section{HIV Knowledge, Testing and Counseling}

The variable of HIV knowledge was scored based on 13 items (Supplementary Table S1). Each correct answer was assigned 1 point, incorrect answers were assigned 0 points. Individuals scoring more than 11 points were considered to have good HIV knowledge, others were considered to have poor HIV knowledge. Additionally, participants were asked to report whether they had undergone HIV testing (yes, no) and whether they had had HIV counseling (yes, no) before the trial.

\section{Substance Use}

There were two aspects of substance use that were assessed: the frequency of alcohol use during the month before the survey (daily, at least 3 times/week, at least 1 time/week, less than 1 time/week, never) and whether illicit drugs (ecstasy or others) had been used during the 6 months before the survey (yes, no).

\section{Medication Adherence During PrEP}

The PrEP adherence in this study was a measure of the medication rate of MSMM during the follow-up period, we calculated the total medication adherence of the study cohort during the total follow-up period. We assigned individuals to the good adherence group if their PrEP medication rate was $\geq 0.6$ and to the poor adherence group if their medication rate was $<0.6 .^{19,20}$ The medication rate of each participant was equal to the total number of pills taken during the whole follow-up period divided by the total number of pills that had been prescribed during the follow-up period. ${ }^{21,22}$ Individuals in the daily medication group were prescribed a number of pills equal to the number of days participating in the follow-up survey, and individuals in the on-demand medication group were prescribed a total number of pills equal to the number of insertion sexual acts during the follow-up period multiplied by 2 . Throughout the follow-up period, the participants were asked whether they had missed any doses and to declare the number of missed doses if so at each follow-up survey. Thus, medication rate in the daily PrEP group $=$ (total number of pills prescribed for the follow-up period - number of missed doses)/total number of pills prescribed for the follow-up period. The medication rate in the on-demand PrEP group $=$ (total number of sexual insertion acts during the follow-up period $\times 2-$ number of missed doses)/(total number of sexual insertion acts during the follow-up period $\times 2$ ). The medication rate for each participant was between 0 and 1 . 


\section{Protection Motivation Theory Model of PrEP Adherence}

We built a Protection Motivation Theory (PMT) model of PrEP adherence for MSMM based on the original PMT put forward by Maddux and Rogers ${ }^{23}$ in 1983. Our PMT model of adherence (Table 1) included two aspects (threat assessment and response assessment) and seven factors (severity, susceptibility, external reward for poor adherence behavior, internal reward for poor adherence behavior, self-efficacy, response benefit, and response cost). We defined 20 variables in seven factors of this scale and based the rating standard of the scale on a five-point Likert scoring method. The participants' knowledge of severity and susceptibility brought by the poor adherence and self-efficacy and response benefit for good adherence were positively scored $(1,2,3,4$, $5)$ according to the degree of occurrence. The higher the score, the stronger the protection motivation of the participants. However, the internal and external rewards brought by poor medication adherence and the response cost of medication taking were scored reversing the order $(5,4,3,2,1)$. The higher the score, the less internal and external rewards, the lower the cost of drug taking, and the stronger the protection motivation. The mean score of each variable for each factor was taken as the final score for that factor, and we expressed it as a mean \pm standard deviation. The Cronbach's $\alpha$ of the PMT scale was 0.66 .

\section{Quality Control and Ethics}

Based on an extensive literature review, the research plan was formulated and subsequently validated by experts in infectious diseases, epidemiology, and health statistics. Investigators and quality controllers were strictly trained, and the logicality and integrity of the questionnaire content were checked. This study followed the Helsinki Declaration and Good Clinical Practice (GCP) guidelines; was approved by the Ethics Committee of Chongqing Medical University; and all the participants signed informed consent forms.

\section{Statistical Analysis}

The study's database was established using the Epidata 3.1 software (EpiData Associations, Odense, Denmark), and we carried out real-time double entry and logical verification of the data. We performed the statistical analysis using the SAS 9.4 software (SAS Institute, Cary, NC, USA). We described continuous data as means \pm standard deviations (SDs), and categorical data as composition ratios and rates. A univariate analysis of PrEP adherence was performed applying the $\chi^{2}$ and rank sum tests, and we used a $t$ test of two independent samples to compare the scores of protective motivation factors between the two adherence groups. Logistic stepwise regression model was conducted to explore the factors influencing the protective motivation of PrEP adherence in MSMM, and the odds ratio(OR) value and $95 \%$ confidence intervals (CIs) were calculated. $p<0.05$ was considered statistically significant.

\section{Results}

\section{General Characteristics}

A total of 2,422 participants from Chongqing, Sichuan, Xinjiang, and Guangxi were recruited, and 496 MSMM were eligible for this study (Figure 1). The average age of MSMM was 30.09 years (median, 28), $74.40 \%$ of them were urban residents, and $89.11 \%$ were of Han origin. The majority of MSMM were well educated, and $59.80 \%$ of them had a college or higher degree. Additionally, 79.39\% of the men had a job, and $9.29 \%$ of them were still students at school. Unmarried MSMM accounted for $71.37 \%$ of the population. The income level was relatively low among the population, only $12.07 \%$ of them had an average monthly income of more than 5000 RMB (Table 2).

Risk of HIV infection: The HIV antibody positivity conversion rate among the MSMM was $9.48 \%$. The same rate was $4.01 \%$ for the MSMM in the good adherence group, and $17.77 \%$ for those in the poor adherence group, with a statistically significant difference $(p<0.0001)$. The HIV antibody positivity conversion rate in the on-demand PrEP group was slightly lower than that in the daily PrEP group, without statistical significance (Table 2).

\section{PrEP Adherence in MSMM}

In this study, the average medication rate for 496 MSMM during the whole follow-up period was 0.64 \pm 0.34 . Among them, 299 MSMM (60.28\%) had good medication adherence with a medication rate $\geq 0.6$ and 197 MSMM (39.72\%) had poor medication adherence 
Table I Scoring of PrEP Adherence Protection Motivation Factors

\begin{tabular}{|c|c|c|c|}
\hline \multicolumn{2}{|l|}{ Factor } & \multirow{2}{*}{$\begin{array}{l}\text { Variable } \\
\text { What do you know about the severity of AIDS? }\end{array}$} & \multirow{2}{*}{$\begin{array}{l}\text { Value Assignment } \\
I=\text { Not serious at all, } 2=\text { Not too serious, } 3=\text { Somewhat } \\
\text { serious, } 4=\text { Serious, } 5=\text { Very serious }\end{array}$} \\
\hline $\begin{array}{l}\text { Threat } \\
\text { assessment }\end{array}$ & Severity & & \\
\hline & & $\begin{array}{l}\text { What do you know about the HIV infection rate } \\
\text { among MSM around you? }\end{array}$ & $I=$ Very low, $2=$ Low, $3=$ Average, $4=$ High, $5=$ Very high \\
\hline & Susceptibility & $\begin{array}{l}\text { How much of a threat do you consider AIDS to } \\
\text { be for you and your family? }\end{array}$ & $\mathrm{I}=$ Very small, $2=$ Small, $3=$ Average, $4=$ Large, $5=$ Very large \\
\hline & $\begin{array}{l}\text { External } \\
\text { reward }\end{array}$ & $\begin{array}{l}\text { What is your male partner's attitude towards } \\
\text { you taking PrEP drugs? }\end{array}$ & $\begin{array}{l}5=\text { Very supportive, } 4 \text { = Moderately supportive; } 3=\text { Not very } \\
\text { supportive } 2 \text { = Comparatively opposed; I = Fully opposed }\end{array}$ \\
\hline & \multirow{2}{*}{$\begin{array}{l}\text { Internal } \\
\text { reward }\end{array}$} & I think it is inconvenient to take the medication & \multirow{2}{*}{$\begin{array}{l}5=\text { Not at all, } 4=\text { Agree a little, } 3=\text { Agree to some extent, } 2= \\
\text { Mostly agree, } 1=\text { Always }\end{array}$} \\
\hline & & I find it very troublesome to take medication & \\
\hline \multirow[t]{14}{*}{$\begin{array}{l}\text { Response } \\
\text { assessment }\end{array}$} & \multirow[t]{8}{*}{ Self-efficacy } & $\begin{array}{l}\text { How do you feel about the prophylaxis: } \\
\text { when HIV preventive drugs are not immediately } \\
\text { available? }\end{array}$ & \multirow[t]{8}{*}{$\begin{array}{l}\text { I = Not confident at all, } 2=\text { Not confident, } 3=\text { Comparatively } \\
\text { confident, } 4=\text { Very confident, } 5=\text { Completely confident }\end{array}$} \\
\hline & & $\begin{array}{l}\text { When you had (recently) been drinking or using } \\
\text { other drugs? }\end{array}$ & \\
\hline & & $\begin{array}{l}\text { When your sex partner is upset about the } \\
\text { medication? }\end{array}$ & \\
\hline & & When you feel medications' side effects? & \\
\hline & & When the burden of HIV is too much? & \\
\hline & & $\begin{array}{l}\text { When you think that your sex partners will not } \\
\text { approve of your use of HIV preventive drugs? }\end{array}$ & \\
\hline & & When you think the risk of AIDS is very low? & \\
\hline & & $\begin{array}{l}\text { When you have used other protective measures } \\
\text { such as condoms? }\end{array}$ & \\
\hline & $\begin{array}{l}\text { Response } \\
\text { benefit }\end{array}$ & I think drugs make me safer and prevent AIDS & $\begin{array}{l}\text { I = Do not agree at all, } 2=\text { Agree a little, } 3=\text { Agree to some } \\
\text { extent, } 4=\text { Mostly agree, } 5=\text { Always }\end{array}$ \\
\hline & \multirow{5}{*}{$\begin{array}{l}\text { Response } \\
\text { cost }\end{array}$} & I am worried that the medication will not work & \multirow{5}{*}{$\begin{array}{l}5=\text { Not at all, } 4=\text { A little, } 3=\text { Somewhat, } 2=\text { Mostly, } I= \\
\text { Always }\end{array}$} \\
\hline & & I worry about the side effects of the medication & \\
\hline & & $\begin{array}{l}\text { I worry about homosexual partners learning that } \\
\text { I am taking medication }\end{array}$ & \\
\hline & & $\begin{array}{l}\text { I worry that others will discriminate me when } \\
\text { they learn I am on medication }\end{array}$ & \\
\hline & & I think the doctors here discriminate me & \\
\hline
\end{tabular}

Abbreviation: PrEP, pre-exposure prophylaxis.

with a medication rate $<0.6$ (Table 3). Moreover, univariate analysis showed significant differences in medication mode, employment status, condom use, and HIV knowledge scores between the two groups ( $\mathrm{p}$ $<0.05)$.

\section{Protection Motivation Scores by Different Adherence Groups}

The protection motivation scores of PrEP adherence in MSMM were calculated according to two aspects and seven factors. According to our analysis, the total scores 


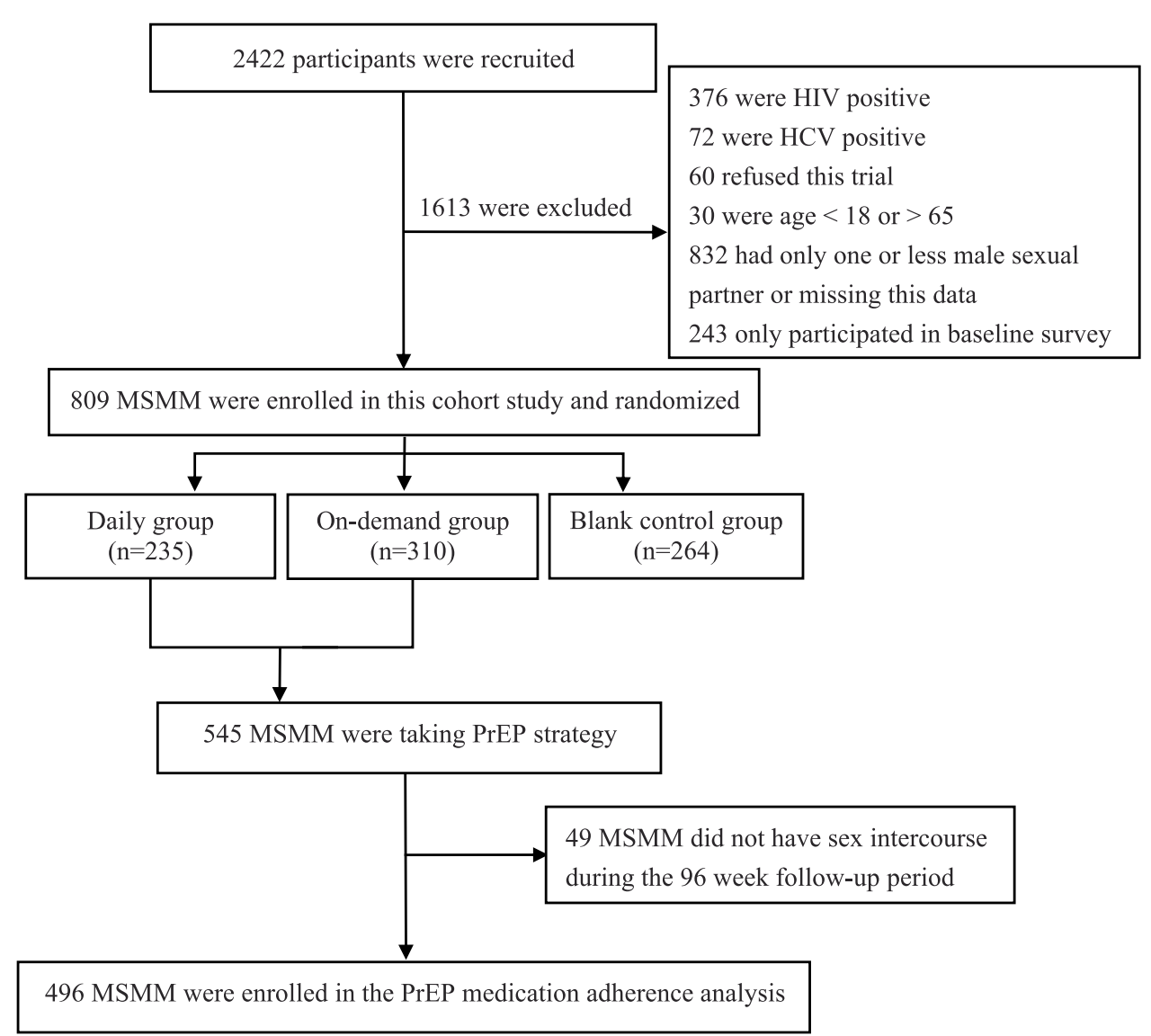

Figure I Flow chart of participants' enrollment.

Abbreviations: MSMM, men who have sex with multiple men; PrEP, pre-exposure prophylaxis.

of threat assessment in the good and poor adherence groups were $2.15 \pm 0.59$ and $2.06 \pm 0.47$, respectively; and the total response assessment scores were $2.81 \pm 0.62$ and $2.74 \pm 0.62$, respectively. Table 4 shows the scores of the seven factors. Among those factors, the good and poor adherence groups presented statistically significant differences in the scores of threat assessment, susceptibility, and response cost $(p<0.05)$.

\section{Multivariate Analysis for Protection Motivation Factors of PrEP Adherence}

Logistic stepwise regression was used in multivariate analysis, with poor medication adherence as the dependent variable (Table 5). We found that the main factors influencing PrEP adherence were medication mode, employment status, condom use, and HIV knowledge score. In addition, the total threat assessment, susceptibility, and response

Table 2 HIV Antibody Positivity Conversion Rate in MSMM

\begin{tabular}{|c|c|c|c|c|c|c|c|c|}
\hline \multirow[t]{2}{*}{ Characteristics } & \multicolumn{2}{|c|}{$\begin{array}{c}\text { Total } \\
(n=496)\end{array}$} & \multicolumn{2}{|c|}{$\begin{array}{l}\text { HIV-Positive } \\
\quad(n=47)\end{array}$} & \multicolumn{2}{|c|}{$\begin{array}{c}\text { HIV-Negative } \\
\quad(n=449)\end{array}$} & \multirow[t]{2}{*}{$\chi^{2}$} & \multirow[t]{2}{*}{$p$-value } \\
\hline & $\mathbf{n}$ & $\%$ & $\mathbf{n}$ & $\%$ & $\mathbf{n}$ & $\%$ & & \\
\hline \multicolumn{9}{|l|}{ Adherence } \\
\hline Good Adherence & 299 & 9.48 & 12 & 4.01 & 287 & 95.99 & 26.1865 & $<0.0001$ \\
\hline Poor Adherence & 197 & 90.52 & 35 & 17.77 & 162 & 82.23 & & \\
\hline \multicolumn{9}{|l|}{ Medication Mode } \\
\hline Daily PrEP group & 213 & 42.94 & 23 & 10.80 & 190 & 89.20 & 0.761 & 0.383 \\
\hline On-demand PrEP group & 283 & 57.06 & 24 & 8.84 & 259 & 91.52 & & \\
\hline
\end{tabular}

Note: Bold value indicates statistical significance with $p<0.05$.

Abbreviations: HIV, human immunodeficiency virus; MSMM, men who have sex with multiple men. 
Table 3 Characteristics of Men Who Have Sex with Multiple Men (MSMM) and Univariate Analysis

\begin{tabular}{|c|c|c|c|c|c|c|c|c|}
\hline \multirow[t]{2}{*}{ Characteristics } & \multicolumn{2}{|c|}{$\begin{array}{c}\text { Total } \\
(n=496)\end{array}$} & \multicolumn{2}{|c|}{$\begin{array}{c}\text { Good } \\
\text { Adherence } \\
(n=299)\end{array}$} & \multicolumn{2}{|c|}{$\begin{array}{c}\text { Poor } \\
\text { Adherence } \\
(n=197)\end{array}$} & \multirow[t]{2}{*}{$\chi^{2}$} & \multirow[t]{2}{*}{$p$-value } \\
\hline & $\mathbf{n}$ & $\%$ & $\mathbf{n}$ & $\%$ & $\mathbf{n}$ & $\%$ & & \\
\hline \multicolumn{9}{|l|}{ Medication mode } \\
\hline Daily PrEP group & 213 & 42.94 & 115 & 53.99 & 98 & 46.01 & 6.1721 & 0.0130 \\
\hline On-demand PrEP group & 283 & 57.06 & 184 & 65.02 & 99 & 34.98 & & \\
\hline \multicolumn{9}{|l|}{ Social demographic characteristics } \\
\hline \multicolumn{9}{|l|}{ Age, years } \\
\hline $18-30$ & 279 & 56.25 & 160 & 57.35 & 119 & 42.65 & 2.2938 & 0.1299 \\
\hline$\geq 31$ & 217 & 43.75 & 139 & 64.06 & 78 & 35.94 & & \\
\hline \multicolumn{9}{|l|}{ Area } \\
\hline Urban & 369 & 74.40 & 223 & 60.43 & 146 & 39.57 & 0.0138 & 0.9065 \\
\hline Rural & 127 & 25.60 & 76 & 59.84 & 51 & 40.16 & & \\
\hline \multicolumn{9}{|l|}{ Ethnic groups } \\
\hline Han nationality & 442 & 89.11 & 262 & 59.28 & 180 & 40.72 & 1.7169 & 0.1901 \\
\hline Other ethnic minorities & 54 & 10.89 & 37 & 68.52 & 17 & 31.48 & & \\
\hline \multicolumn{9}{|l|}{ Educational level $^{\#}$} \\
\hline Junior high or below & 60 & 12.12 & 36 & 60.00 & 24 & 40.00 & 2.8615 & $0.2391 *$ \\
\hline Senior high & 139 & 28.08 & 76 & 54.68 & 63 & 45.32 & & \\
\hline College or above & 296 & 59.80 & 187 & 63.18 & 109 & 36.82 & & \\
\hline \multicolumn{9}{|l|}{ Employment status } \\
\hline Employed & 393 & 79.39 & 240 & 61.07 & 153 & 38.93 & 6.2405 & $0.044 I$ \\
\hline Students at school & 46 & 9.29 & 32 & 69.57 & 14 & 30.43 & & \\
\hline Retired or unemployed & 56 & $|1.3|$ & 26 & 46.43 & 30 & 53.57 & & \\
\hline \multicolumn{9}{|l|}{ Marital status } \\
\hline Unmarried & 354 & 71.37 & 214 & 60.45 & 140 & 39.55 & 0.0719 & 0.9647 \\
\hline Married & 88 & 17.74 & 52 & 59.09 & 36 & 40.91 & & \\
\hline Divorce or widowhood & 54 & 10.89 & 33 & 61.11 & 21 & 38.89 & & \\
\hline \multicolumn{9}{|l|}{ Personal monthly income (RMB) } \\
\hline$\leq 3000$ & 250 & 51.12 & 153 & 61.20 & 97 & 38.80 & 1.0400 & 0.5945 \\
\hline $300 I-5000$ & 180 & 36.81 & 110 & 61.11 & 70 & 38.89 & & \\
\hline$\geq 5001$ & 59 & 12.07 & 32 & 54.24 & 27 & 45.76 & & \\
\hline \multicolumn{9}{|l|}{ Sexual behavior characteristics } \\
\hline \multicolumn{9}{|l|}{ The sex position during anal sexual intercourse with men $^{\#}$} \\
\hline Only doing insertive anal sex "I" & 114 & 23.03 & 65 & 57.02 & 49 & 42.98 & 4.7163 & 0.3177 \\
\hline Both but "I" mainly & 131 & 26.46 & 77 & 58.78 & 54 & 41.22 & & \\
\hline Both equally & 131 & 26.46 & 89 & 67.94 & 42 & 32.06 & & \\
\hline Both but " 0 " mainly & 76 & 15.35 & 42 & 55.26 & 34 & 44.74 & & \\
\hline Only doing receptive anal sex "0" & 43 & 8.69 & 25 & 58.14 & 18 & 41.86 & & \\
\hline \multicolumn{9}{|l|}{ Temporary male sexual partners in the past 6 months ${ }^{\#}$} \\
\hline 0 & 67 & 13.65 & 37 & 55.22 & 30 & 44.78 & 1.5970 & 0.4500 \\
\hline I & 150 & 30.55 & 96 & 64.00 & 54 & 36.00 & & \\
\hline$\geq 2$ & 274 & 55.80 & 164 & 59.85 & 110 & 40.15 & & \\
\hline
\end{tabular}

(Continued) 
Table 3 (Continued).

\begin{tabular}{|c|c|c|c|c|c|c|c|c|}
\hline \multirow[t]{2}{*}{ Characteristics } & \multicolumn{2}{|c|}{$\begin{array}{c}\text { Total } \\
(n=496)\end{array}$} & \multicolumn{2}{|c|}{$\begin{array}{c}\text { Good } \\
\text { Adherence } \\
(n=299)\end{array}$} & \multicolumn{2}{|c|}{$\begin{array}{c}\text { Poor } \\
\text { Adherence } \\
(n=197)\end{array}$} & \multirow[t]{2}{*}{$\chi^{2}$} & \multirow[t]{2}{*}{$p$-value } \\
\hline & $\mathbf{n}$ & $\%$ & $\mathbf{n}$ & $\%$ & $\mathbf{n}$ & $\%$ & & \\
\hline \multicolumn{9}{|c|}{ Female sexual partners in the past 6 months ${ }^{\#}$} \\
\hline 0 & $4 I I$ & 84.57 & 250 & 60.83 & 161 & 39.17 & 1.9623 & 0.3749 \\
\hline I & 69 & 14.20 & 43 & 62.32 & 26 & 37.68 & & \\
\hline$\geq 2$ & 6 & 1.23 & 2 & 33.33 & 4 & 66.67 & & \\
\hline \multicolumn{9}{|c|}{ Frequency of condom use when having anal sex with men } \\
\hline Always & 282 & 58.51 & 183 & 64.89 & 99 & 35.11 & 7.5582 & 0.0228 \\
\hline Occasionally & 172 & 35.68 & 91 & 52.91 & 81 & 47.09 & & \\
\hline Never & 28 & 5.81 & 14 & 50.00 & 14 & 50.00 & & \\
\hline \multicolumn{9}{|c|}{ Frequency of Internet-seeking sexual partners in the past 6 months ${ }^{\#}$} \\
\hline Often & 47 & 9.49 & 30 & 63.83 & 17 & 36.17 & 4.4665 & 0.1072 \\
\hline Sometimes or occasionally & 348 & 70.30 & 217 & 62.36 & $|3|$ & 37.64 & & \\
\hline Never & 100 & 20.20 & 51 & 51.00 & 49 & 49.00 & & \\
\hline \multicolumn{9}{|c|}{ Whether a commercial sexual service in the past 6 months } \\
\hline Yes & 38 & 7.66 & 24 & 63.16 & 14 & 36.84 & 0.1421 & 0.7062 \\
\hline No & 458 & 92.34 & 275 & 60.04 & 183 & 39.96 & & \\
\hline \multicolumn{9}{|c|}{ Diagnosed with STD in the past 6 months } \\
\hline Yes & 54 & 10.95 & 27 & 50.00 & 27 & 50.00 & 2.6567 & 0.1031 \\
\hline No & 439 & 89.05 & 270 & 61.50 & 169 & 38.50 & & \\
\hline \multicolumn{9}{|c|}{ HIV knowledge and testing and counseling } \\
\hline \multicolumn{9}{|l|}{ HIV voluntary testing } \\
\hline Yes & 409 & 82.46 & 252 & 61.61 & 157 & 38.39 & 1.7264 & 0.1889 \\
\hline No & 87 & 17.54 & 47 & 54.02 & 40 & 45.98 & & \\
\hline \multicolumn{9}{|l|}{ HIV voluntary counseling ${ }^{\#}$} \\
\hline Yes & 326 & 65.99 & 203 & 62.27 & 123 & 37.73 & 1.8456 & 0.1743 \\
\hline No & 168 & 34.01 & 94 & 55.95 & 74 & 44.05 & & \\
\hline \multicolumn{9}{|l|}{ HIV knowledge score } \\
\hline$\leq I I$ & 231 & 46.57 & 124 & 53.68 & 107 & 46.32 & 7.8723 & 0.0050 \\
\hline$>11$ & 265 & 53.43 & 175 & 66.04 & 90 & 33.96 & & \\
\hline \multicolumn{9}{|l|}{ Substance use } \\
\hline \multicolumn{9}{|c|}{ Frequency of alcohol use in the last month } \\
\hline Daily & 17 & 3.43 & 9 & 52.94 & 8 & 47.06 & 1.7413 & 0.7832 \\
\hline At least 3 times/week & 48 & 9.68 & 29 & 60.42 & 19 & 39.58 & & \\
\hline At least I time/week & 80 & 16.13 & 44 & 55.00 & 36 & 45.00 & & \\
\hline Less than I time/week & 201 & 40.52 & 123 & 61.19 & 78 & 38.81 & & \\
\hline Never & 150 & 30.24 & 94 & 62.67 & 56 & 37.33 & & \\
\hline \multicolumn{9}{|c|}{$\begin{array}{l}\text { Whether illicit drugs (ecstasy, methamphetamine, k powder } \\
\text { (ketamine), etc) used in the last half year }{ }^{\#}\end{array}$} \\
\hline No & 472 & 96.72 & 285 & 60.38 & 187 & 39.62 & 1.7811 & 0.1820 \\
\hline Yes & 16 & 3.28 & 7 & 43.75 & 9 & 56.25 & & \\
\hline
\end{tabular}

Notes: *Rank sum test, and $\chi^{2}$ test was used for the rest. ${ }^{\#}$ Indicates loss of data, the average missing rates of variables were $<0.9 \%$. Bold values indicate statistical significance with $p<0.05$. 
Table 4 Comparison of Protection Motivation Scores in MSMM from Different Adherence Groups

\begin{tabular}{|c|c|c|c|c|}
\hline \multirow[t]{2}{*}{ Protection Motivation Factors } & $\begin{array}{c}\text { Good Adherence } \geq \\
0.6 \\
(n=299)\end{array}$ & $\begin{array}{c}\text { Poor } \\
\text { Adherence }<0.6 \\
(n=197)\end{array}$ & \multirow[t]{2}{*}{$\boldsymbol{t}$} & \multirow[t]{2}{*}{$p$-value } \\
\hline & Mean \pm SD & Mean \pm SD & & \\
\hline Threat assessment & $2.15 \pm 0.59$ & $2.06 \pm 0.47$ & 2.02 & 0.0443 \\
\hline Severity & $1.78 \pm 0.59$ & $1.78 \pm 0.63$ & -0.03 & 0.9728 \\
\hline Susceptibility & $1.96 \pm 1.28$ & $1.65 \pm 0.93$ & 3.10 & 0.0021 \\
\hline External reward & $2.49 \pm 1.02$ & $2.54 \pm 1.03$ & -0.51 & $0.607 \mid$ \\
\hline Internal reward & $2.39 \pm 1.07$ & $2.26 \pm 1.02$ & 1.37 & 0.1709 \\
\hline Response assessment & $2.81 \pm 0.62$ & $2.74 \pm 0.62$ & 1.24 & 0.2162 \\
\hline Self-efficacy & $2.87 \pm 0.75$ & $2.79 \pm 0.75$ & 1.18 & 0.2391 \\
\hline Response benefit & $3.14 \pm 1.32$ & $3.18 \pm 1.39$ & -0.30 & 0.7639 \\
\hline Response cost & $2.43 \pm 0.73$ & $2.26 \pm 0.76$ & 2.45 & 0.0147 \\
\hline
\end{tabular}

Notes: Analysis using a t-test of two independent samples. Bold values indicate statistical significance with $p<0.05$.

Abbreviations: MSMM, men who have sex with multiple men; SD, standard deviation.

cost scores were negatively correlated with poor medication adherence $(p<0.05)$.

MSMM who were still students at school belonged to a high-risk group for poor PrEP adherence, and they were 1.837 times more likely to have poor adherence than MSMM having a job (OR=1.837, 95\% CI: 1.024-3.299). Individuals in the ondemand PrEP mode were less likely to present poor adherence than those in the daily PrEP medication group $(\mathrm{OR}=0.670$, 95\% CI: 0.458-0.978). Moreover, the risk of poor adherence in MSMM with occasional condom use was 1.621 times higher than that in MSMM who always used condoms ( $\mathrm{OR}=1.621$, 95\% CI: 1.091-2.409). In addition, good HIV knowledge was a protective factor predicting good medication adherence, MSMM with knowledge scores $>11$ were less likely to have poor medication adherence $(\mathrm{OR}=0.565,95 \% \mathrm{CI}$ : 0.385 $0.828)$.

The regression analysis showed that the PrEP adherence of MSMM correlated with protection motivation factors. The higher the threat assessment score of an individual, the less likely that individual was to belong to the poor medication adherence group ( $\mathrm{OR}=0.685,95 \%$ CI: $0.481-0.976$ ). Among MSMM, the higher the HIV susceptibility perception, the less likely they were to present poor medication adherence ( $\mathrm{OR}=0.785$, 95\% CI: 0.659-0.936). Similarly, in the response assessment for an individual, the higher the response cost score, the smaller the response cost of PrEP medication, and the less likely that individual was to develop poor medication adherence (OR $=0.639,95 \%$ CI: $0.491-0.832)$.

Dependent variable $=$ poor PrEP adherence. In the logistic regression analysis, model 1 only included variables with $p<$ 0.05 in the univariate analysis as the independent variables; model 2 included threat assessment and response assessment in addition to those in model 1; model 3 included 7 factors of protection motivation in addition to those in model 1, including severity, susceptibility, external reward, internal reward, selfefficacy, response benefit, and response cost.

\section{Discussion}

\section{PrEP Adherence Characteristics in MSMM}

To achieve the global goal of "END AIDS" in 2030, a UNAIDS report in 2018 showed that we still have "MILES TO GO"24 and the consideration of key HIV prevention groups at present is not enough. Under the Chinese traditional moral concepts, MSM are discriminated against and frequently encounter psychological barriers. ${ }^{25}$ The majority of MSM have multiple sexual partners, ${ }^{26}$ and MSMM have become a high-risk group for HIV infection. Our study found that in the strictly managed follow-up cohort of HIV-negative MSM undergoing PrEP in Western China, MSMM who reported poor adherence scores $<0.6$ accounted for nearly $40 \%$ of the cohort (a concerning proportion). The HIV antibody positivity rate of individuals in the poor adherence group was $17.77 \%$, significantly higher than the $4.01 \%$ of the individuals in the good adherence group, in agreement with the results of a South African study ${ }^{12}$ showing that poor adherence seriously affects the PrEP effectiveness. Based on these results, we believe that the study of the management of medication adherence risks is particularly important in MSMM. 
Table 5 Multivariate Logistic Stepwise Regression Analysis of PrEP Adherence Among MSMM

\begin{tabular}{|c|c|c|c|c|c|}
\hline \multirow[t]{2}{*}{ Model } & \multirow[t]{2}{*}{ Independent Variable } & \multirow[t]{2}{*}{ p-value } & \multirow[t]{2}{*}{ OR } & \multicolumn{2}{|c|}{ 95\% Cl for OR } \\
\hline & & & & Lower & Upper \\
\hline \multirow[t]{14}{*}{ Model I } & & & & & \\
\hline & Employment status & & & & \\
\hline & Employed (reference) & & & & \\
\hline & Students at school & 0.042 & 1.837 & 1.024 & 3.299 \\
\hline & Retired or unemployed & 0.180 & 0.629 & 0.319 & 1.240 \\
\hline & Medication mode & & & & \\
\hline & Daily PrEP group (reference) & & & & \\
\hline & On-demand PrEP group & 0.038 & 0.670 & 0.458 & 0.978 \\
\hline & $\begin{array}{l}\text { Frequency of condom use when having anal sex with } \\
\text { men }\end{array}$ & & & & \\
\hline & Always (reference) & & & & \\
\hline & Occasionally & 0.017 & 1.621 & $1.09 \mid$ & 2.409 \\
\hline & Never & 0.257 & 1.591 & 0.713 & 3.550 \\
\hline & $\begin{array}{l}\text { HIV knowledge score } \\
\quad \leq \mathrm{II} \text { (reference) }\end{array}$ & & & & \\
\hline & $>11$ & 0.004 & 0.565 & 0.385 & 0.828 \\
\hline \multirow[t]{12}{*}{ Model 2} & & & & & \\
\hline & Threat assessment score & 0.036 & 0.685 & $0.48 I$ & 0.976 \\
\hline & Medication Mode & & & & \\
\hline & Daily PrEP group (reference) & & & & \\
\hline & On-demand PrEP group & 0.049 & 0.683 & 0.466 & 0.999 \\
\hline & $\begin{array}{l}\text { Frequency of condom use when having anal sex with } \\
\text { men }\end{array}$ & & & & \\
\hline & Always (reference) & & & & \\
\hline & Occasionally & 0.019 & 1.607 & 1.080 & 2.391 \\
\hline & Never & 0.183 & 1.736 & 0.770 & 3.911 \\
\hline & HIV knowledge score & & & & \\
\hline & $\leq \mathrm{II}$ (reference) & & & & \\
\hline & $>$ II & 0.009 & 0.602 & 0.411 & 0.880 \\
\hline \multirow[t]{9}{*}{ Model 3} & & & & & \\
\hline & Susceptibility score & 0.007 & 0.785 & 0.659 & 0.936 \\
\hline & Response cost score & 0.001 & 0.639 & 0.491 & 0.832 \\
\hline & $\begin{array}{l}\text { Frequency of condom use when having anal sex with } \\
\text { men }\end{array}$ & & & & \\
\hline & Always (reference) & & & & \\
\hline & Occasionally & 0.012 & 1.673 & 1.121 & 2.498 \\
\hline & Never & 0.274 & 1.567 & 0.701 & 3.504 \\
\hline & $\begin{array}{l}\text { HIV knowledge score } \\
\quad \leq \mathrm{II} \text { (reference) }\end{array}$ & & & & \\
\hline & $>11$ & 0.034 & 0.659 & 0.447 & 0.969 \\
\hline
\end{tabular}

Note: Bold values indicate statistical significance with $p<0.05$.

Abbreviations: $\mathrm{Cl}$, confidence interval; OR, odds ratio; MSMM, men who have sex with multiple men; PrEP, pre-exposure prophylaxis. 
We also found that most MSMM in China tend to be young (56.25\% aged 30 and below) and highly educated (59.80\% with a college or higher degree), nearly $10 \%$ of participants were still students at school (a rate than that seen in 2010). ${ }^{27} \mathrm{In}$ addition, our multivariate analysis showed that MSMM who were still students at school were 1.837 times more likely to have poor PrEP adherence than MSMM who were employed, which may be due to the young age of students and their poor self-protection awareness. Moreover, most students in China live in university campuses, and this collective life means students lack personal privacy spaces and worry about being discriminated if classmates and roommates find their PrEP medication. Taking medication produces a "stigma effect" 24 which results in students not taking their medication in a timely manner or refusing to take it at all. Therefore, follow-up research should pay more attention to students and strengthen school AIDS education. ${ }^{28}$

In the MSMM population, condom use was also correlated with PrEP adherence, and MSMM with "occasional condom use" were more likely to have poor adherence than those with "always condom use" $(\mathrm{OR}=1.625)$, which may make things worse. In addition, previous study ${ }^{29}$ also indicated that MSM on PrEP often hold the view that the risk of HIV infection is reduced; however, men on PrEP increase their frequency of unprotected sexual encounters. International studies have recommended daily medications, ${ }^{30}$ but we found that MSMM are not prone to poor adherence when taking PrEP on demand $(\mathrm{OR}=0.683)$, and we believe this may be because taking drugs before and after sexual behavior can make men feel that the prevention effect is better. In addition, in a comparison of medication regimens by Anderson et $\mathrm{al}^{31}{ }^{31}$ in the MSM using on-demand PrEP, the dosage of medication before and after sexual behavior is smaller, the cost smaller and the frequency of side effects lower than those in MSM using daily PrEP, and these advantages are conducive to long-term medication adherence in the on-demand group. Based on our results, MSMM with poor condom use is not conducive to PrEP adherence and HIV prevention, and medication on demand may be an effective mode for PrEP.

\section{Protection Motivation Factors of PrEP Adherence}

The PMT model is widely used to help researchers find the protection motivation factors that promote healthy behaviors and inhibit the occurrence of bad behaviors, to plan precise interventions. However, the efficacy of the model has not been demonstrated in the study of PrEP adherence in China, and our study is the first one to explore the protection motivation of PrEP adherence among MSMM populations. Our results show that the poor PrEP adherence of MSMM was negatively correlated with the total threat assessment score $(\mathrm{OR}=0.685)$, the susceptibility score $(\mathrm{OR}=0.785)$, and the response cost score $(\mathrm{OR}=0.639)$. In other words, the higher the threat perception and the stronger the susceptibility of the MSMM in our study, the higher the protection motivation for PrEP adherence; and, the higher the response cost score, the lower the cost, and the higher the PrEP adherence. In accordance with the study by Chambers on Indian American youth, ${ }^{32}$ our results provide a theoretical basis for targeted PrEP interventions through the PMT model with follow-up studies. PMT has been widely applied for interventions on type 2 diabetes and other chronic diseases requiring long-term medication, and studies have shown that the adherence in the intervention groups is better than those in the control groups. ${ }^{33}$ We believe that PMT can be applied to MSMM population interventions as an effective scheme to improve PrEP adherence and to prevent new HIV infections.

In this study, the susceptibility score of the good adherence group $(1.96 \pm 1.28)$ was significantly higher than that of the poor adherence group $(1.65 \pm 0.93)$, and the total threat assessment score was relatively high. Consistent with the study of Xiao et al, ${ }^{34}$ our results indicate that when MSMM recognize that poor adherence can lead to a decrease in physical defense, their perceived HIV susceptibility and threat increases, which in turn increases their protection motivation promotes improved PrEP adherence.

In terms of response assessment, we found that the response cost score was correlated with the medication adherence. The response cost was scored reversely, that is, the higher the response cost score of taking medication, the lower the cost, the stronger the protection motivation for PrEP, and the less likely the MSMM population were to have poor adherence behaviors $(\mathrm{OR}=0.639)$. Moreover, PrEP studies ${ }^{35,36}$ have also confirmed that MSM worries about side effects of drugs and stigma affect their motivation of for PrEP adherence. Thus, in a future study, PrEP pills should be optimized to ensure privacy for their users.

We found no significant differences in self-efficacy between good and poor adherence groups. It may be that MSMM have a diverse sex life, leading them to present poor PrEP adherence, as reflected on our results (nearly $40 \%$ of MSMM showed poor adherence). Moreover, the average selfefficacy score in the good adherence group was slightly higher than that in the poor adherence group. In agreement with a study in Russia, ${ }^{37}$ the MSMM with better HIV knowledge in 
our study showed better adherence; however, other studies ${ }^{21}$ have found a certain "separation between knowledge and practice" in MSM. It may be that most MSMM in our study had a high education level and a better understanding of the risk of infection caused by high-risk sexual behaviors, so their PrEP adherence was better than that of the participants with poor knowledge. This suggests that increasing the HIV knowledge by MSMM and improving the medication self-efficacy (minimizing the cost of taking PrEP) may enhance the protection motivation of MSMM to improve their PrEP adherence.

\section{Limitations}

This study had several limitations. First, this was a realworld study of MSMM, and some factors may not be fully included. Second, the PrEP adherence assessment was derived from self-reporting by participants and may have errors. Third, although we carried out a sensitivity analysis between the MSMM in the adherence analysis and those not included in it (Supplementary Table S2), the follow-up work was challenging and may be biased due to the particularities of this population. Our team has started using an intelligent monitoring system to obtain more objective medication information for subsequent studies.

\section{Conclusions}

This study focused on PrEP adherence by MSMM in Western China, we found that students at school, those with poor HIV knowledge, and those with occasional condom use are high-risk groups with poor PrEP adherence, and that ondemand PrEP (medication before and after sexual behavior) may lead to appropriate adherence by MSMM. In addition, our results indicated that the protection motivation for PrEP adherence in the MSMM population was not strong, and that adherence was associated with their threat assessment, susceptibility, and response cost.

Therefore, the government and health-related departments should strengthen AIDS education in schools, focus on improving the AIDS knowledge of the public and key populations, and promote the use of condoms. Increasing susceptibility, reducing medication costs, and emphasizing threat assessment will help improve the PrEP adherence in the MSMM population. Moreover, a customized PMT scale can be used to screen for PrEP adherence by MSMM in the future; also, applying a PMT scale to intervention research may provide a constructive reference for effective HIV infection prevention and risk management in MSMM.

\section{Acknowledgments}

We thank all participants and investigators in Chongqing, Sichuan, Xinjiang and Guangxi provinces in China for their help.

\section{Funding}

This work was supported by the National Key Project for Infectious Diseases of the Ministry of Science and Technology of China (2012ZX10001007-007 and 2018ZX10721102-005); and Chongqing Science and Technology Commission (No. cstc2013jcyjA10009).

\section{Disclosure}

The authors declared no conflicts of interest for this work.

\section{References}

1. UNAIDS. Unaids data 2017. Availabe from: http://www.unaids.org/ sites/default/files/media_asset/20170720_Data_book_2017_en.pdf. Accessed February 2, 2020.

2. Chow EPF, Lau JTF, Zhuang X, Zhang X, Wang Y, Zhang LJ. HIV prevalence trends, risky behaviours, and governmental and community responses to the epidemic among men who have sex with men in China. Clin Infect Dis. 2014;2014:1-19. doi:10.1155/2014/607261

3. Wu Z, Jie X, Liu E, et al. HIV and syphilis prevalence among men who have sex with men: a cross-sectional survey of 61 Cities in China. Clin Infect Dis. 2013;57(2):298-309. doi:10.1093/cid/cit210

4. National Center for AIDS/STD Control and Prevention China CDC. National HIV/Syphilis/HCV Sentinel Surveillance Report in 2017. Beijing: NationalCenter for AIDS/STD Control and Prevention China CDC; 2017.

5. Wu Z. Characteristics of HIV sexually transmission and challenges for controlling the epidemic in China. Zhonghua liu Xing Bing Xue Za Zhi. 2018;39(6):707-709. doi:10.3760/cma.j.issn.02546450.2018.06.002

6. UNAIDS. 2014. Gay men and other men who have sex with men. Availabe from:https://www.unaids.org/sites/default/files/media_asset/ UNAIDS_Gap_report_en.pdf. Accessed March 6, 2020.

7. Yin L, Zhao Y, Peratikos MB, et al. Risk Prediction Score for HIV infection: development and internal validation with cross-sectional data from men who have sex with men in China. AIDS Behav. 2018;22(7):2267-2276. doi:10.1007/s10461-018-2129-y

8. Deepti C, Icard LD, Jemmott JB, et al. Prospective predictors of multiple sexual partners among African American men who have sex with men. Arch Sex Behav. 2018;47(7):2081-2090. doi:10.1007/ s10508-018-1207-6

9. Crosland GEMD, Carl K, Laio M, et al. Comparing HIV risk-related behaviors between 2 RDS national samples of MSM in Brazil, 2009 and 2016. Medicine. 2018;97:S62-S8. doi:10.1097/MD.0000000000009079

10. Office of the Working Committee on AIDS prevention and control of the State Council of China, Ministry of health of China, United Nations China task force on AIDS. China joint assessment report on AIDS prevention and control (2007) 2007.

11. Zhang Yue CF, Ding F, Lin X, et al. Status of multiple sexual partners and its correlates among HIV-positive men who have sex with men. Chinese J Aids STD. 2017;8:734-737. doi:10.13419/j.cnki.aids.2017.08.16;.

12. Abdool Karim Q, Abdool Karim SS, Frohlich JA, et al. Effectiveness and safety of tenofovir gel, an antiretroviral microbicide, for the prevention of HIV infection in women. Science. 2010;329 (5996):1168-1174. doi:10.1126/science. 1193748 
13. Baeten JM, Donnell D, Ndase P, Mugo NR, Med CC. Antiretroviral prophylaxis for HIV prevention in heterosexual men and women. $N$ Engl Journal of Med. 2012;367(5):399-410. doi:10.1056/ NEJMoa1108524

14. Choopanya K, Martin M, Suntharasamai P, et al. Antiretroviral prophylaxis for HIV infection in injecting drug users in Bangkok, Thailand (the Bangkok Tenofovir Study): a randomised, doubleblind, placebo-controlled Phase 3 trial. The Lancet. 2013;381 (9883):2083-2090. doi:10.1016/S0140-6736(13)61127-7

15. Taylor D, Amico KR, Brown E Asking about and measuring adherence. Paper presented at: The International Microbicides Conference, Sydney, Australia.2012, April:15-18.

16. Gao F-FZX-N, Peng B, Zhang Y, et al. Pre-exposure prophylaxis for HIV high-risk groups: an analysis of clinical compliance. Acad J Second Military Med Univ. 2012;033(11):1186-1193.

17. Bassett SF, Prapavessis H. A test of an adherence enhancing adjunct to physiotherapy steeped in the Protection Motivation Theory. Physiother Theory Pract. 2011;27(5):360-372. doi:10.3109/09593985.2010.507238

18. Bjornstad P, Pyle L, Nguyen N. Achieving International Society for Pediatric and Adolescent Diabetes and American Diabetes Association clinical guidelines offers cardiorenal protection for youth with type 1 diabetes. J Pediatr Diabetes. 2015;16(1):22-30. doi:10.1111/pedi.12252

19. Grant RM, Anderson PL. An observational study of preexposure prophylaxis uptake, sexual practices, and HIV incidence among men and transgender women who have sex with men. Lancet Infect Dis. 2014;14(9):820-829. doi:10.1016/S1473-3099(14)70847-3

20. Hendrix CWJ. Exploring concentration response in HIV pre-exposure prophylaxis to optimize clinical care and trial design. Cell. 2013;155 (3):515-518. doi:10.1016/j.cell.2013.09.030

21. Qu D, Zhong X, Xiao G, Dai J, Liang H, Huang A. Adherence to preexposure prophylaxis among men who have sex with men: a prospective cohort study. Int J Infect Dis. 2018;75:52-59. doi:10.1016/j. ijid.2018.08.006

22. Hu Y, Zhong X, Peng B, et al. Associations between perceived barriers and benefits of using HIV pre-exposure prophylaxis and medication adherence among men who have sex with men in Western China. BMC Infect Dis. 2018;18(1):575. doi:10.1186/ s12879-018-3497-7

23. Maddux JE, Rogers RW. Protection motivation and self-efficacy: a revised theory of fear appeals and attitude change. J Exp Soc Psychol. 1983;19(5):0-479. doi:10.1016/0022-1031(83)90023-9

24. UNAIDS. Miles to go - closing gaps, breaking barriers, righting injustices. Availabe from: https://www.unaids.org/en/resources/docu ments/2018/global-aids-update. Accessed March 10, 2020.

25. Liu J, Zhong X, Lu Z, et al. Anxiety and depression associated with anal sexual practices among HIV-negative men who have sex with men in Western China. Int J Environ Res Public Health. 2020;17(2). doi:10.3390/ijerph17020464
26. Yue C, Xiangyu M, Hong W, Minjin P, Yah hong SL. Prevalence of AIDS-related sexual behaviors and HIV infection status in young men who have sex with men in China: a Meta-analysis. Chinese $J$ Epidemiol. 2016;7:1021-1027.

27. Zhou J-B, Wang J-T, Guo Y-L, et al. Study of influencing factors associated with multi-sexual partners and infection of HIV and syphilis among men who have sex with men in Changzhou. Chinese $J$ Dermatovenereol. 2013;27(4):371-373.

28. Batchelder AW, Safren S, Mitchell AD, Ivardic I, O'Cleirigh C. Mental health in 2020 for men who have sex with men in the United States. Sex Health. 2017;14(1):59. doi:10.1071/SH16083

29. Morgan E, Moran K, Ryan DT, Mustanski B, Newcomb MEJAB. Threefold Increase in PrEP uptake over time with high adherence among young men who have sex with men in Chicago. AIDS Behav. 2018;22(11):3637-3644. doi:10.1007/s10461-018-2122-5

30. Centers for Disease Control and Prevention. Pre-exposure prophylaxis for the prevention of HIV infection in the United States - 2014: a clinical practice guideline. Availabe from: http://www.cdc.gov/hiv/ pdf/prepguidelines2014.pdf[EB/OL]. Accessed March 82020.

31. Anderson PL, García-Lerma JG, Wj H. Nondaily preexposure prophylaxis for HIV prevention. Current opinion in HIV and AIDS. Aids. 2015;11(1):94-101. doi:10.1097/COH.0000000000000213

32. Chambers R, Tingey L, Mullany B, Parker S, Lee A, Barlow AJAC. Exploring sexual risk taking among American Indian adolescents through protection motivation theory. AIDS Care. 2016;28(9):10891096. doi:10.1080/09540121.2016.1164289

33. Xuehui Z, Ning Z. Influence of nursing intervention based on protection motivation theory on medication compliance and quality of life of patients with type 2 diabetes mellitus. Nurs Res. 2015;12 (36):4500. doi:10.3969/j.issn.1009-6493.2015.36.006

34. Xiao C, Chen X, Wang T, Liu M, Li Shiyue HY. Analysis on medication adherence of HIV/AIDS patients based on the protection motivation theory. Chinese J Aids STD. 2017;6:503-506.

35. Poloko M, Kebaabetswe M, Stirratt J, et al. Factors associated with adherence and concordance between measurement strategies in an HIV daily oral tenofovir/emtricitibine as pre-exposure prophylaxis (Prep) clinical trial, Botswana, 2007-2010. AIDS\&Behavior. 2015;19 (5):758-769. doi:10.1007/s10461-014-0891-z

36. Peter Mwangi Mugo EJS, Mutua G, van der Elst E, et al. Understanding adherence to daily and intermittent regimens of oral HIV pre-exposure prophylaxis among men who have sex with men in Kenya. AIDS Behav. 2015;19(5):794-801. doi:10.1007/s10461-0140958-x

37. Amirkhanian YA, Kelly JA, Kukharsky AA, et al. Predictors of HIV risk behavior among Russian men who have sex with men: an emerging epidemic. Aids. 2001;15(3):407-412. doi:10.1097/00002030200102160-00014

\section{Publish your work in this journal}

Risk Management and Healthcare Policy is an international, peerreviewed, open access journal focusing on all aspects of public health, policy, and preventative measures to promote good health and improve morbidity and mortality in the population. The journal welcomes submitted papers covering original research, basic science, clinical \& epidemiological studies, reviews and evaluations, guidelines, expert opinion and commentary, case reports and extended reports. The manuscript management system is completely online and includes a very quick and fair peer-review system, which is all easy to use. Visit http://www.dovepress.com/testimonials.php to read real quotes from published authors. 